Corrigendum

\title{
Corrigendum to "Metformin Decreases Reactive Oxygen Species, Enhances Osteogenic Properties of Adipose-Derived Multipotent Mesenchymal Stem Cells In Vitro, and Increases Bone Density In Vivo"
}

\author{
Krzysztof Marycz, ${ }^{1,2}$ Krzysztof A. Tomaszewski, ${ }^{3}$ Katarzyna Kornicka, \\ Brandon Michael Henry, ${ }^{3}$ Sebastian Wroński, ${ }^{4}{ }^{3}$ Jacek Tarasiuk, ${ }^{4}$ and Monika Maredziak ${ }^{2,5}$ \\ ${ }^{1}$ Electron Microscopy Laboratory, Wroclaw University of Environmental and Life Sciences, $5 b$ Kozuchowska Street, \\ 51-631 Wroclaw, Poland \\ ${ }^{2}$ Wroclaw Research Centre EIT+, 147 Stablowicka Street, 54-066 Wroclaw, Poland \\ ${ }^{3}$ Department of Anatomy, Jagiellonian University Medical College, 12 Kopernika Street, 31-034 Krakow, Poland \\ ${ }^{4}$ Faculty of Physics and Applied Computer Science, AGH University of Science and Technology, 30 Mickiewicza Street, \\ 30059 Krakow, Poland \\ ${ }^{5}$ Department of Animal Physiology and Biostructure, Faculty of Veterinary Medicine, Wroclaw University of Environmental and Life \\ Sciences, 31 Norwida Street, 50-375 Wroclaw, Poland
}

Correspondence should be addressed to Krzysztof Marycz; krzysztofmarycz@interia.pl

Received 10 May 2017; Accepted 24 May 2017; Published 20 August 2017

Copyright (C) 2017 Krzysztof Marycz et al. This is an open access article distributed under the Creative Commons Attribution License, which permits unrestricted use, distribution, and reproduction in any medium, provided the original work is properly cited.

In the article titled "Metformin Decreases Reactive Oxygen Species, Enhances Osteogenic Properties of AdiposeDerived Multipotent Mesenchymal Stem Cells In Vitro, and Increases Bone Density In Vivo" [1], an acknowledgment should be added as follows:

\section{Acknowledgments}

This publication was supported by the Wrocław Centre of Biotechnology, programme The Leading National Research Centre (KNOW) for years 2014-2018.

\section{References}

[1] K. Marycz, K. A. Tomaszewski, K. Kornicka et al., "Metformin Decreases Reactive Oxygen Species, Enhances Osteogenic Properties of Adipose-Derived Multipotent Mesenchymal Stem Cells In Vitro, and Increases Bone Density In Vivo," Oxidative Medicine and Cellular Longevity, vol. 2016, Article ID 9785890, 19 pages, 2016 


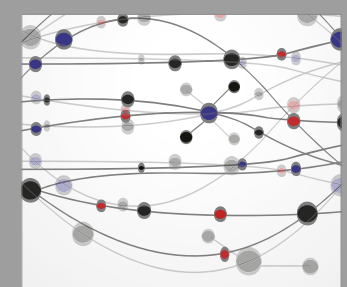

The Scientific World Journal
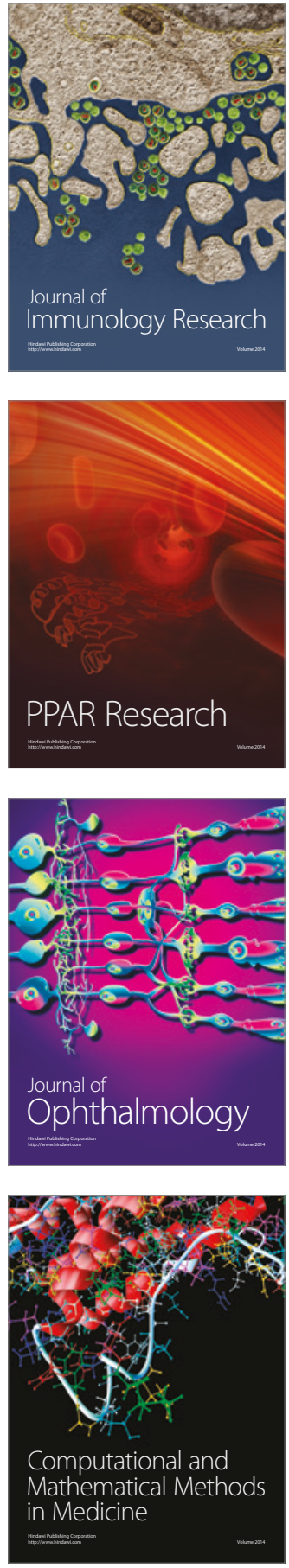

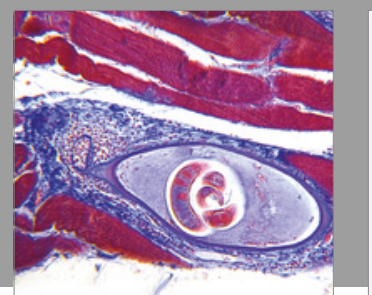

Gastroenterology Research and Practice
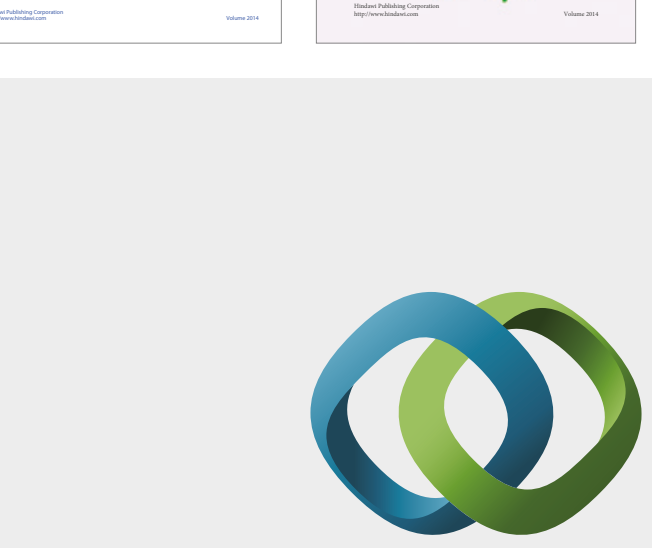

\section{Hindawi}

Submit your manuscripts at

https://www.hindawi.com
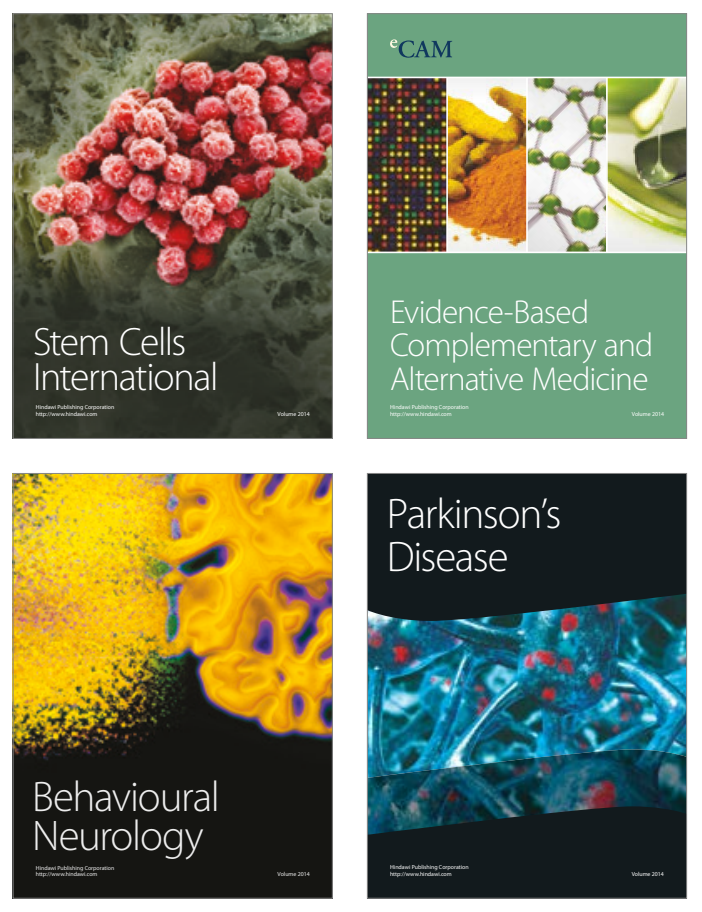
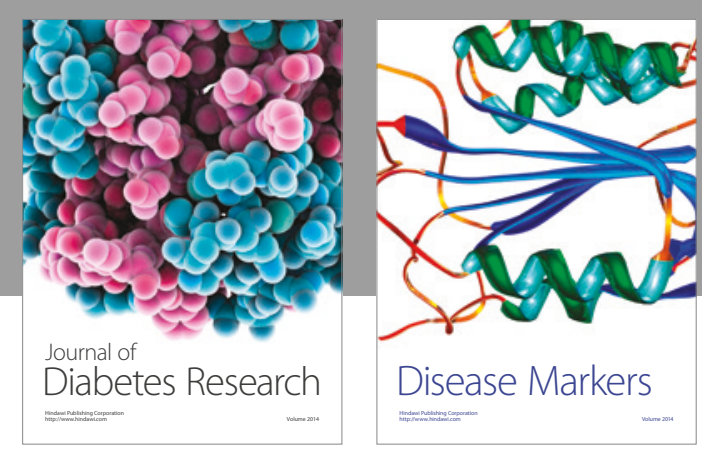

Disease Markers
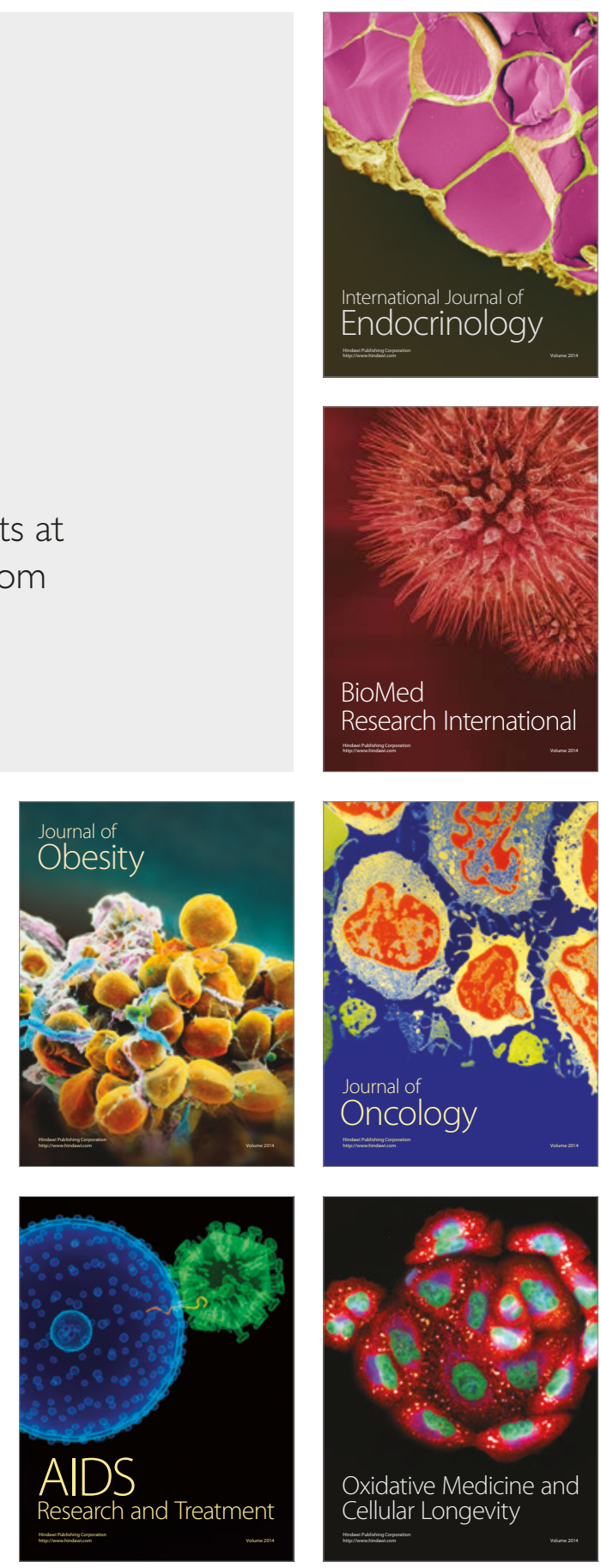